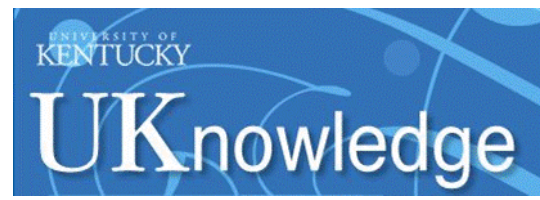

University of Kentucky

UKnowledge

Toxicology and Cancer Biology Faculty

Publications

Toxicology and Cancer Biology

4-2018

\title{
Extracellular Vesicles Released by Cardiomyocytes in a Doxorubicin-Induced Cardiac Injury Mouse Model Contain Protein Biomarkers of Early Cardiac Injury
}

\author{
Chontida Yarana \\ University of Kentucky, chon.yarana@uky.edu \\ Dustin W. Carroll \\ University of Kentucky, dca225@uky.edu \\ Jing Chen \\ University of Kentucky, jchen4@email.uky.edu \\ Luksana Chaiswing \\ University of Kentucky, I.chaiswing@uky.edu \\ Yanming Zhao \\ University of Kentucky, yzhao@uky.edu \\ Follow this and additional works at: https://uknowledge.uky.edu/toxicology_facpub \\ see next of the fancer Badiology Cedthmors \\ Right click to open a feedback form in a new tab to let us know how this document benefits you.
}

\section{Repository Citation}

Yarana, Chontida; Carroll, Dustin W.; Chen, Jing; Chaiswing, Luksana; Zhao, Yanming; Noel, Teresa; Alstott, Michael; Bae, Younsoo; Dressler, Emily V.; Moscow, Jeffrey A.; Butterfield, D. Allan; Zhu, Haining; and St.

Clair, Daret K., "Extracellular Vesicles Released by Cardiomyocytes in a Doxorubicin-Induced Cardiac Injury Mouse Model Contain Protein Biomarkers of Early Cardiac Injury" (2018). Toxicology and Cancer Biology Faculty Publications. 82.

https://uknowledge.uky.edu/toxicology_facpub/82

This Article is brought to you for free and open access by the Toxicology and Cancer Biology at UKnowledge. It has been accepted for inclusion in Toxicology and Cancer Biology Faculty Publications by an authorized administrator of UKnowledge. For more information, please contact UKnowledge@lsv.uky.edu. 
Extracellular Vesicles Released by Cardiomyocytes in a Doxorubicin-Induced Cardiac Injury Mouse Model Contain Protein Biomarkers of Early Cardiac Injury

Digital Object Identifier (DOI)

https://doi.org/10.1158/1078-0432.CCR-17-2046

Notes/Citation Information

Published in Clinical Cancer Research, v. 24, issue 7, 1644-1653.

(C) 2017 American Association for Cancer Research

The copyright holder has granted the permission for posting the article here.

The document available for download is the authors' post-peer-review final draft of the article.

Authors

Chontida Yarana, Dustin W. Carroll, Jing Chen, Luksana Chaiswing, Yanming Zhao, Teresa Noel, Michael Alstott, Younsoo Bae, Emily V. Dressler, Jeffrey A. Moscow, D. Allan Butterfield, Haining Zhu, and Daret K. St. Clair 
Published in final edited form as:

Clin Cancer Res. 2018 April 01; 24(7): 1644-1653. doi:10.1158/1078-0432.CCR-17-2046.

\title{
Extracellular vesicles released by cardiomyocytes in a doxorubicin-induced cardiac injury mouse model contain protein biomarkers of early cardiac injury
}

\author{
Chontida Yarana ${ }^{1,2}$, Dustin Carroll ${ }^{1}$, Jing Chen ${ }^{3}$, Luksana Chaiswing ${ }^{1}$, Yanming Zhao ${ }^{1}$, \\ Teresa Noel ${ }^{1}$, Michael Alstott ${ }^{4}$, Younsoo Bae ${ }^{5}$, Emily V. Dressler ${ }^{6}$, Jeffrey A. Moscow ${ }^{7}$, D. \\ Allan Butterfield ${ }^{4,8}$, Haining Zhu ${ }^{1,3,4}$, and Daret K. St. Clair ${ }^{1,}{ }^{*}$ \\ ${ }^{1}$ Department of Toxicology and Cancer Biology, University of Kentucky, Lexington, KY, USA \\ ${ }^{2}$ Faculty of Medical Technology, Mahidol University, Salaya, Thailand ${ }^{3}$ Department of Molecular \\ and Cellular Biochemistry, University of Kentucky, Lexington, KY, USA ${ }^{4}$ Markey Cancer Center, \\ Redox Metabolism Shared Resource Facility, University of Kentucky, Lexington, KY, USA \\ ${ }^{5}$ Department of Pharmaceutical Sciences, University of Kentucky, Lexington, KY, USA ${ }^{6}$ Division of \\ Biostatistical Sciences, Wake Forest School of Medicine, Winston-Salem, NC, USA \\ ${ }^{7}$ Investigational Drug Branch, National Cancer Institute, Bethesda, MD, USA ${ }^{8}$ Department of \\ Chemistry, University of Kentucky, Lexington, KY, USA
}

\section{Abstract}

Purpose-Cardiac injury is a major cause of death in cancer survivors, and biomarkers for it are detectable only after tissue injury has occurred. Extracellular vesicles (EVs) remove toxic biomolecules from tissues and can be detected in the blood. Here, we evaluate the potential of using circulating EVs as early diagnostic markers for long-term cardiac injury.

Experimental Design-Using a mouse model of doxorubicin (DOX)-induced cardiac injury, we quantified serum EVs, analyzed proteomes, measured oxidized protein levels in serum EVs released after DOX treatment, and investigated the alteration of EV content.

\begin{abstract}
Results-Treatment with DOX caused a significant increase in circulating EVs (DOX_EVs) compared to saline-treated controls. DOX_EVs exhibited a higher level of 4-hydroxynonenal adducted proteins, a lipid peroxidation product linked to DOX-induced cardiotoxicity. Proteomic profiling of DOX_EVs revealed the distinctive presence of brain/heart, muscle, and liver isoforms of glycogen phosphorylase (GP), and their origins were verified to be heart, skeletal muscle, and liver, respectively. The presence of brain/heart GP (PYGB) in DOX_EVs correlated with a reduction of PYGB in heart, but not brain tissues. Manganese superoxide dismutase (MnSOD)
\end{abstract}

Corresponding Author: Daret K. St. Clair, PhD, 458 Health Sciences Research Building, Department of Toxicology and Cancer Biology, University of Kentucky, Lexington, KY 40536 USA, Phone: 859-257-3956; Fax: 859-323-1059; dstc100@uky.edu.

Authors' Contributions:

Development of methodology: CY, JC, LC, MA, DC

Acquisition of data: CY, TN, YB, JAM, DAB, HZ, YZ

Analysis and interpretation of data: CY, EVD

Writing and review of manuscript: All

Administrative, conceptual, and material support: DS 
overexpression, as well as pretreatment with cardioprotective agents and MnSOD mimetics, resulted in a reduction of EV-associated PYGB in mice treated with DOX. Kinetic studies indicated that EVs containing PYGB were released prior to the rise of cardiac troponin in the blood after DOX treatment, suggesting that PYGB is an early indicator of cardiac injury.

Conclusion-EVs containing PYGB are an early and sensitive biomarker of cardiac injury.

\section{Keywords}

Extracellular vesicles; chemotherapy; oxidative stress; cardiac injury; biomarkers

\section{Introduction}

Chemotherapy can damage normal cells as well as cancer cells, and can therefore result in late onset of side effects that compromise patient survivorship and quality of life. According to the American Cancer Society's Surveillance and Health Services Research, as of 2014, around 6 million cancer survivors had lived longer than ten years since their diagnosis (1). Although they survived their cancer, these patients may unfortunately suffer from complications of treatment, ranging from non-fatal conditions such as cognitive dysfunction, neuropathy, and infertility, to life-threatening conditions such as cardiomyopathy, myelodysplastic syndrome, and secondary malignancy (2). Severe adverse effects of chemotherapy can also have a substantial economic impact due to hospitalizations and prescriptions, costs for which are estimated at around $\$ 12,907$ and $\$ 1,908$ per person per year, respectively (3). This estimation reaffirms the significance of preventing cancer treatment-related adverse effects.

With the exception of secondary malignancies, cardiovascular disease is the leading cause of death among cancer survivors (4). Anthracyclines, especially doxorubicin (DOX), are the most common chemotherapeutic agents that cause cardiomyopathy. However, their effectiveness and broad efficacy against more types of cancer than any other class of chemotherapy make anthracyclines a frequently used drug class (5).

DOX-induced cardiomyopathy presents as a decline of left ventricular function that can develop many years after treatment cessation (6). Cardiac troponin-I (cTnI) and troponin-T $(\mathrm{cTnT})$ are validated serological biomarkers for DOX-induced cardiotoxicity. Although these biomarkers are specific in predicting adverse outcomes from high-dose radiation and chemotherapy, the evidence for low and moderate doses, as well as in asymptomatic childhood cancer survivors, remains unclear $(7,8)$. Moreover, they are released after cardiac cell death occurs, which is not an early event in the development of chemotherapy-induced cardiotoxicity. Thus, it is not optimal to start cardioprotective interventions based on cTnI or cTnT levels.

DOX-induced cardiotoxicity and other normal tissue injury begin with the generation of reactive oxygen species (ROS) and reactive nitrogen species (RNS), predominantly in the mitochondria $(9,10)$. Excess ROS/RNS results in oxidative damage to biomolecules such as lipids, DNA, and proteins. Oxidative modification of lipids and proteins leads to mitochondrial dysfunction (11) and consequently activates cell death pathways (12). To 
maintain cellular homeostasis, the cells can remove oxidized proteins in several ways, e.g., through ubiquitin/proteasome-mediated degradation, autophagy, and extracellular vesicles (EVs). However, recent evidence has shown that extensive and sustained oxidative stress during chemotherapy impairs cellular ability to degrade oxidized proteins via the ubiquitin/ proteasome and autophagy pathways (13-15). Therefore, EVs could be a major mechanism for oxidized protein elimination during chemotherapy-induced tissue injury. We hypothesized that circulating EVs could indicate the level of oxidative stress in targeted tissue during chemotherapy and that they could be used as a liquid biopsy for highly sensitive biomarkers of tissue injury resulting from chemotherapy.

EVs are membrane-bound structures released from most cell types into the extracellular compartment. EVs are categorized into three types, based on size and the mechanisms of biogenesis. Exosomes $(50-100 \mathrm{~nm})$ originate from inward budding of the endosomal membrane, forming multivesicular bodies, and are released by fusion of the multivesicular body membrane with the plasma membrane. Microvesicles $(0.2-2.0 \mu \mathrm{m})$ are derived from plasma membrane blebbing. Apoptotic bodies $(1-2 \mu \mathrm{m})$ are membranous globules released during apoptotic processes (16).

EVs are attractive for biomarker discovery for many reasons. First, EVs are stable in the extracellular environment because of the lipid bilayer that protects their cargo from enzymatic degradation (17). Second, EVs are highly abundant in plasma/serum, with an estimated concentration around $10^{10} \mathrm{EVs}$ per $\mathrm{mL}$ (18). Third, EVs carry proteins, lipids, and nucleic acids that reflect their tissues of origin and the condition of the releasing cells $(19,20)$. However, little is known about the oxidative status, content, or tissue origin for circulating EVs generated by chemotherapy-induced tissue injury.

In the present study, we investigated the protein content of EVs to determine the potential profile for early detection of cardiac injury after DOX treatment. We found that EVs present after DOX treatment contained signatures of cardiac tissue and high levels of protein-bound 4-hydroxynonenal (4HNE), which can be alleviated by enhancing tissue antioxidant capacity. Moreover, the EVs and their protein contents are more sensitive than conventional serological biomarkers for detection of DOX-induced tissue injury.

\section{Materials and Methods}

\section{Animals and treatment}

Male C57BL/6J mice 10-12 weeks of age and 25-28 g in body weight were injected intraperitoneally (IP) with a single $20 \mathrm{mg} / \mathrm{kg}$ dose of doxorubicin hydrochloride (DOX; Bedford Laboratories, Inc., Bedford, OH, USA) or saline (SAL). All mouse-related procedures followed the American Veterinary Medical Association Guidelines for the Care and Use of Laboratory Animals and were approved by the Institutional Animal Care and Use Committee at the University of Kentucky. Blood was collected at 1, 24, 48 and $72 \mathrm{~h}$ after treatment. To avoid heart tissue injury during blood collection, we collected blood from the inferior vena cava. Blood was allowed to clot by incubation at room temperature for at least $30 \mathrm{~min}$. The clot was pelleted by centrifugation at $1,300 \mathrm{~g}$ for $15 \mathrm{~min}$, and the serum was collected and stored at $-80^{\circ} \mathrm{C}$. 
For the indicated experiments, dexrazoxane (DRZ; Zinecard®, and Upjohn Company LLC, Division of Pfizer Inc., NY) was administered at $200 \mathrm{mg} / \mathrm{kg}$ IP $30 \mathrm{~min}$ before DOX treatment as recommended in the clinical use guide (21). The manganese superoxide dismutase (MnSOD) mimetic Mn(III) meso-tetrakis ( $N$-(n-butoxyethyl)pyridium-2yl)porphyrin, MnTnBuOE-2-PyP ${ }^{5+}(\mathrm{MnP})$, was kindly provided by Dr. Ines Batinic-Haberle and colleagues (Duke University School of Medicine, Durham, NC, USA). In the indicated experiments, $\mathrm{MnP}$ was IP injected at $2 \mathrm{mg} / \mathrm{kg} 30 \mathrm{~min}$ prior to DOX treatment.

\section{Serum EV isolation}

For proteomic analysis, mouse serum EVs were isolated by sucrose gradient centrifugation as previously described (22) with modifications. One $\mathrm{mL}$ of serum was layered on top of a 10-70\% sucrose gradient in SW55 tubes (Beckman Coulter Inc., Brea, CA, USA) with subsequent centrifugation at 100,000 g overnight. Fractions three to five, which contained EV markers CD63 and CD81 (Supplementary Figure 1A and B), were collected. Each fraction was diluted in phosphate-buffered saline (PBS) and EV pellets obtained by centrifugation at 100,000 $\mathrm{g}$ for $70 \mathrm{~min}$. The pellets from each fraction were resuspended in PBS and pooled. Sucrose was removed by a final centrifugation of the pooled suspension at $100,000 \mathrm{~g}$ for $70 \mathrm{~min}$.

For all other procedures, ExoQuick precipitation solution (System Biosciences, Mountain View, CA, USA) was used to isolate EVs. From 200-250 $\mu \mathrm{L}$ of mouse serum, cells and cellular debris were pelleted by centrifugation at $3,000 \mathrm{~g}$ for $15 \mathrm{~min}$, and $50-63 \mu \mathrm{L}$ of ExoQuick solution were added to the supernatants. The mixture was incubated at $4{ }^{\circ} \mathrm{C}$ for 30 $\mathrm{min}$, and the EV pellet was obtained by centrifugation at 1,500 $\mathrm{g}$ for $30 \mathrm{~min}$. The supernatant was aspirated, and the residual ExoQuick solution was removed without disturbing the pellets after centrifugation at $1,500 \mathrm{~g}$ for $5 \mathrm{~min}$. EV pellets were resuspended in sterile water or PBS and stored at $-80{ }^{\circ} \mathrm{C}$.

\section{Transmission electron microscopy (TEM)}

Fresh, unfrozen EV pellets were resuspended in $2 \%$ paraformaldehyde and adsorbed onto Formvar-carbon coated grids. The samples were fixed with $1 \%$ glutaraldehyde followed by staining with uranyl oxalate, and were then embedded in a mixture of $4 \%$ uranyl acetate and $2 \%$ methylcellulose. EVs were visualized by TEM at $80 \mathrm{kV}$ (23) (Supplementary Figure $1 \mathrm{C})$.

\section{EV quantification and size measurement}

EVs in PBS suspension were quantified by measuring protein concentration using the bicinchoninic acid method. For size measurement, the EV suspension was diluted with PBS to a concentration of $100 \mu \mathrm{g} / \mathrm{mL}$. The size distribution of EVs was evaluated by dynamic light scattering using the Zetasizer Nano ZS (Malvern, Worcestershire, UK). The laser was operated at a $173^{\circ}$ angle with temperature set at $4{ }^{\circ} \mathrm{C}$.

\section{Protein-bound 4HNE measurement}

EVs from DOX- or SAL-treated mice (DOX_EVs and SAL_EVs, respectively) were lysed with radioimmunoprecipitation assay (RIPA) buffer and the lysates were mixed with an 
equal volume of Laemmli buffer. Protein-bound $4 \mathrm{HNE}$ levels were assessed by slot blot as previously described (24). The protein bands were visualized and the intensities were quantified by Adobe Photoshop (San Jose, CA, USA) and Scion Image, respectively. Band intensities for protein-bound 4HNE for DOX_EVs were normalized by those obtained from SAL_EVs, and reported as a fold change after the treatment.

\section{Sample preparation for mass spectrometry (MS)}

EV samples from sucrose gradient centrifugation were lysed with RIPA buffer and sonicated at room temperature for $30 \mathrm{sec}, 3$ times. Equal protein aliquots $(10 \mu \mathrm{g})$ from SAL_EV and DOX_EV samples were used for proteomic analysis. EV lysates were reduced with $\beta$ mercaptoethanol and heated to $95{ }^{\circ} \mathrm{C}$ for $5 \mathrm{~min}$. The samples were electrophoresed on an $8 \%$ SDS-PAGE gel at $60 \mathrm{~V}$ for $15 \mathrm{~min}$ to allow protein migration into the top of the gel. After Ruby staining for visualization, the protein bands were excised and subjected to liquid chromatography/tandem MS (LC-MS/MS) (Supplementary Figure 1A).

\section{LC-MS/MS}

Proteomic analysis was performed by the University of Kentucky Proteomics Core Facility. Protein samples, processed as indicated above, were reduced with dithiothreitol, alkylated by iodoacetamide, and digested by a standard protocol of in-gel trypsin digestion. Shotgun proteomic analysis was used as described previously (25). The tryptic peptides were subjected to nano-LC-MS/MS analysis using an LTQ-Orbitrap mass spectrometer (Thermo Fisher Scientific, Waltham, MA) coupled with an Eksigent Nanoflex cHiPLC ${ }^{\text {TM }}$ system (Eksigent, Dublin, CA) through a nano-electrospray ionization source.

\section{MS/MS protein identification}

The LC-MS/MS data were submitted to a local Mascot server. Proteins were identified by Proteome Discoverer (version 1.3, Thermo Fisher Scientific) against a Mus musculus taxonomy subset of the Swissprot database. Proteomic analysis was performed twice. A decoy database was built and searched. Filter settings that determine false discovery rates were used to distribute the confidence indicators for the peptide matches. Peptide matches that pass the filter associated with the strict false discovery rates (with target setting of 0.01) were assigned as high confidence. Peptides that were identified in both experiments on either the DOX_EVs or the SAL_EVs were considered unambiguous.

\section{Western blot analysis}

EVs or serum samples were lysed with RIPA buffer, mixed in Laemli buffer with or without beta-mercaptoethanol, and separated by electrophoresis through an 8\% SDS-PAGE gel. Proteins were transferred to nitrocellulose membranes. The blots were blocked with Odyssey ${ }^{\circledR}$ Blocking Buffer (LI-COR, Lincoln, NE, USA) and incubated overnight at $4{ }^{\circ} \mathrm{C}$ with the primary antibodies. Primary antibodies used in this study were: anti-CD63 (1:200; Santa Cruz, Santa Cruz, CA, USA), anti-Alix (1:200; Santa Cruz), anti-HSC70 (1:200, Santa Cruz), anti-brain/heart glycogen phosphorylase (PYGB) (1:500, Abgent), anti-muscle glycogen phosphorylase (PYGM) (1:500, Bioss, Woburn, MA, USA), anti-liver glycogen phosphorylase (PYGL) (1:500, GeneTex, Irvine, CA. USA), anti-vinculin (1:200, Santa 
Cruz), and anti-tubulin (1:200, Santa Cruz). After several washes, the blots were incubated with IRDye ${ }^{\circledR}$ anti-mouse, rabbit, or goat secondary antibodies (LI-COR) at a dilution of 1:5000 to $1: 10,000$ for $1 \mathrm{~h}$ at room temperature. Washed membranes were scanned and the band intensities measured by the Odyssey Imaging System.

\section{EV immunoprecipitation}

SAL_EVs, DOX_EVs $(400 \mu \mathrm{g})$, and DOX-treated heart tissue were immunoprecipitated with 4HNE-coated beads. 4HNE antibody was purchased from Abcam (Cambridge, MA). SureBeads ${ }^{\mathrm{TM}}$ protein A magnetic beads were purchased from Bio-rad (Hercules, CA). After incubation at $4{ }^{\circ} \mathrm{C}$ overnight, the beads were magnetized and the supernatants were collected. Immunoprecipitated EVs were lysed with RIPA buffer. Supernatant EVs were lysed with RIPA buffer and concentrated with $3 \mathrm{kDa}$ centrifugal filters (MilliporeSigma, Norwood, $\mathrm{OH}$ ) to get a sample equal in volume to the immunoprecipitated EVs.

Albumin/IgG removal kit (Thermo Fisher Scientific, Rockford, IL) was used to eliminate albumin and $\mathrm{IgG}$, which can mask the identification of the proteins of interest. Then all of the sample lysates were mixed with Laemmli buffer and boiled at $95^{\circ} \mathrm{C}$ for $5 \mathrm{~min}$ before running gel electrophoresis.

\section{Measurement of serum protein biomarkers for tissue injuries}

Cardiac injury was assessed by measuring serum cTnI levels from SAL- and DOX-treated mice. Creatine kinase isoenzyme MM (CKMM) and alanine transferase (ALT) were used as biomarkers for skeletal muscle and liver injury, respectively. Values were obtained using commercial ELISA kits as follows: cTnI (Life Diagnostic, West Chester, PA), CKMM (LifeSpan Biosciences, Seattle, WA), and ALT (MyBioSource, San Diego, CA).

\section{Statistical analysis}

Differences between means of GP isoforms in tissues and in EVs, as well as cTnI, ALT, and CKMM comparing between SAL- and DOX-treated mice were analyzed by Student's 2 sample $t$-test. Differences between means for DOX-treated and other parameters were analyzed by a two way repeated measures ANOVA followed by Tukey's test for post-hoc comparisons. $P$-values $<0.05$ are considered statistically significant.

\section{Results}

\section{DOX_EVs had aberrant morphology and larger size when compared to SAL_EVs}

To investigate if DOX treatment affected the characteristics of circulating EVs, SAL_EVs and DOX_EVs were visualized by TEM. The morphology of EVs observed under highmagnification TEM revealed that SAL_EVs were round, membranous structures with a smooth surface. In contrast, the membrane of DOX_EVs was irregular and the size of the vesicles was larger than that of SAL_EVs (Figure 1A). The difference in EV size was confirmed by dynamic light scattering analysis, which also showed that DOX_EVs had a broader size distribution $(13.9 \pm 3.5$ to $204.0 \pm 46.4 \mathrm{~nm})$ compared to SAL_EVs $(4 \pm 0.6$ to $123 \pm 34.8 \mathrm{~nm}$ ) (Figure 1B). 
To verify that the pellets from the ExoQuick precipitation were composed of EVs, equal amounts of pellets derived from SAL- or DOX-treated mouse serum were subjected to immunoblotting to detect the proteins that were enriched in the EVs. Proteins specific to EVs include CD63 (a tetraspanin protein expressed on cellular membranes, including exosomes and microvesicles) and Alix (an endosomal sorting complex required for transport). CD63 and Alix were detected in pellets from SAL_EVs and DOX_EVs. However, calnexin, an endoplasmic reticulum protein commonly detected in apoptotic bodies, could not be identified in the EV samples (Supplementary Figure 2). This result suggests that the pellets from the isolation process represented exosomes and microvesicles but not apoptotic bodies.

\section{Increased levels of circulating EVs and protein-bound 4HNE after DOX treatment}

In order to assess the change in the amount of serum EVs over time, we quantified serum EVs by measuring protein levels in the EV pellets isolated from equal volumes of serum at 1,24 , and $72 \mathrm{~h}$ after treatment. While the amount of serum EV protein after SAL treatment remained unchanged, the amount of EV protein significantly increased over time after DOX treatment, beginning at $24 \mathrm{~h}$ (Figure 2A). The increase in serum EV quantity after DOX treatment was confirmed by TEM (Figure 2B).

4HNE is a major lipid peroxidation product that appears in cell membranes during oxidative stress. 4HNE is highly reactive and can adduct to biomolecules, resulting in functional changes in those molecules. Here we found that circulating EVs contained higher proteinbound 4HNE levels after DOX treatment (Figure 2C). The protein-bound 4HNE levels peaked as early as $24 \mathrm{~h}$ post-DOX treatment and remained higher than SAL-treated controls at $72 \mathrm{~h}$.

\section{Serum EV proteomic profile was altered after DOX treatment}

To identify EV protein contents that might indicate the tissues of origin and potential function of EVs during DOX-induced tissue injury, we performed proteomic analysis of DOX_EVs and SAL-EVs after $72 \mathrm{~h}$ of treatment. Figure 3A shows the number of proteins identified in SAL_EVs and DOX_EVs. The proteomic profiling identified 197 proteins expressed in both SAL_EVs and DOX_EVs (Supplementary Table 1). Among the proteins enriched only in SAL_EVs, transferrin receptor 1 (TfR1) and class I histocompatibility antigen (MHC-I) were identified with high confidence, with ion scores above 50 (Figure 3B). In contrast, haptoglobin (Hp) and glycogen phosphorylase (GP) isoforms from brain (PYGB), muscle (PYGM), and liver (PYGL) were uniquely expressed in DOX_EVs (Figure $3 \mathrm{C})$.

\section{EVs containing tissue-specific GP were released from DOX target tissues}

GP is a tissue-specific protein with isoforms expressed in a tissue-specific manner, as indicated by their names. PYGB is highly expressed in heart and brain, PYGM is highly expressed in skeletal muscle, and PYGL is highly expressed in the liver (Supplementary Figure 3). Because heart/brain, liver and skeletal muscle are organs known to be affected by DOX, the presence of these GP isoforms in serum EVs might serve as potential biomarkers of DOX-induced tissue injury. 
Western blot analysis showed that all three GP isoforms as well as the EV marker, HSC70, were enriched in DOX_EVs as compared to total serum (Figure 4A). All isoforms were scarcely detected in the serum, confirming that they were highly enriched in the EV fraction rather than released as soluble proteins. The existence of PYGB, PYGM, and PYGL inside the EVs was further confirmed by their resistance to proteinase $\mathrm{K}$ digestion due to the protection of the lipid bilayer (Supplementary Figure 4). These data clearly confirmed the proteomic data that PYGB, PYGM, and PYGL were only detected in DOX_EVs and not in SAL_EVs. The levels of PYGB, PYGM, and PYGL were also examined in heart, brain, skeletal muscle, and liver tissues, respectively. Upon DOX treatment, PYGB was significantly decreased in heart tissue, but not in brain tissue, suggesting that it was released from damaged heart tissue of DOX-treated animals (Figures 4B and 4C). This result is consistent with the notion that DOX did not cross the blood brain barrier (BBB), and thus the brain is not a direct target tissue of DOX. A significant but small change in PGYB level in the heart may be due, in part, to the high concentration of PGYB in heart muscle (26). Similarly, PYGM levels decreased in skeletal muscle and PYGL decreased in the liver after DOX treatment (Figures 4B and 4C). These results suggest that EVs that contained PYGB, PYGM, and PYGL were released from the heart, skeletal muscle, and liver, respectively.

\section{EVs with 4HNE adduction but not $4 \mathrm{HNE}$-free EVs were released from DOX target tissues}

Because EVs can contain oxidative stress markers such as $4 \mathrm{HNE}$-adducted proteins and tissue-specific proteins such as GPs in the same structure, we investigated further if EVs containing protein-bound $4 \mathrm{HNE}$ were released from specific DOX target tissues. In this way, EVs might reveal their tissue of origin and the etiology of cellular stress that induced their release. To this end, we immunoprecipitated serum EVs with anti-4HNE antibody and compared the tissue-specific GPs in those EVs to the protein profile in EVs that were not 4HNE bound. PYGB, PYGL, and PYGM were detected in 4HNE pull-downs but not in the supernatant (Figure 5A). The PGYL and PGYM changes in SAL-EV and DOX-EV were small in comparison to PGYB. Moreover, EV markers flotillin-1 and HSC70 were more strongly detected in the pull-downs than in the supernatant. This result suggested that the majority of circulating EVs are 4HNE-adducted and that these EVs are released from DOX target tissues that have high oxidative stress.

Next, we investigated if the level of EV-associated protein-bound 4HNE can be changed by enhancing antioxidant capacity. First, we measured the level of protein-bound 4HNE from serum EVs of MnSOD transgenic (MnSOD Tg) mice that express approximately two-fold higher MnSOD level (9) compared to wild-type mice. In SAL-treated MnSOD Tg mice, the level of EV-associated protein-bound 4HNE did not differ from wild-type mice. However, after DOX treatment, MnSOD Tg mice had significantly lower levels of protein-bound 4HNE than the wild-type mice (Figure 5B).

To determine if exogenously supplied antioxidants can exert a protective effect similar to that observed in the transgenic mice, we used two antioxidant-enhancing drugs, $\mathrm{MnP}$ and DRZ, as tools to study the effect of exogenous antioxidants on EV-associated protein-bound 4HNE levels. MnP is a MnSOD mimetic, redox-active compound that works similar to endogenous MnSOD and has been shown to have a preference for mitochondria (27) as well 
as protect against DOX-induced cardiotoxicity (12). DRZ is a clinically approved drug for anthracycline-induced cardiotoxicity prevention. DRZ acts as an antioxidant by removing iron from iron-DOX complexes (28). DRZ acts as a strong iron chelator following the opening of its two bisdioxopiperazine rings (29). We found that MnP pretreatment but not DRZ pretreatment significantly reduced the level of EV-associated protein-bound 4HNE when compared to DOX treatment alone (Figure 5C).

DOX-induced cardiotoxicity is the most concerning side effect of cancer treatment. Since the amount of EVs released directly correlates with the degree of tissue oxidative stress, we further measured the amount of EVs released from heart tissue by using PYGB as a specific cardiac marker. To calculate the total amount of EV-encapsulated PYGB (EV_PYGB) in 200 $\mu \mathrm{L}$ of serum, the western blot band intensities were normalized by the total amount of EV protein in $200 \mu \mathrm{L}$ of serum from each mouse. The results showed that $\mathrm{EV}$ released from heart tissues as indicated by EV_PYGB in wild-type and MnSOD Tg mice did not change after SAL treatment. However, EV_PYGB in DOX-treated MnSOD Tg mice was significantly lower than DOX-treated wild-type mice (Figure 5D and Supplementary Figure 5B). The decrease in serum EV_PYGB was associated with more retention of PYGB in heart tissue of DOX-treated MnSOD Tg mice compared to DOX-treated wild-type mice (Figure 5E and Supplementary Figure 5B). Pretreatment with exogenous antioxidants that have cardioprotective effects such as $\mathrm{MnP}$ and DRZ significantly decreased the level of EV_PYGB in DOX-treated mice when compared to DOX treatment alone (Figure 5F and Supplementary Figure 5C). However, MnP was more effectively prevented EV release from heart tissue than DRZ (Figure 5F and Supplementary Figure 5C). The level of serum EV_PYGB after antioxidant treatment was also associated with the retention of PYGB in heart tissue (Figure 5G and Supplementary Figure 5C).

\section{EV-encapsulated GPs are sensitive indicators of DOX-induced tissue injury}

Because EV release is a compensatory mechanism that the cell uses to remove toxic molecules before cell death occurs, EVs could be a sensitive biomarker for predicting tissue injury resulting from chemotherapy. Here, we compared the sensitivity of EV-encapsulated GPs to the conventional tissue injury markers such as cTnI for heart injury, ALT for liver injury, and CKMM for muscle injury. The data from western blotting showed clearly that the levels of EV_PYGB, EV_PYGM, and EV_PYGL were significantly increased in DOXtreated mice (Figures 6A-6C and Supplementary Figure 5A). We did not use any EV protein markers for normalization because the markers are uniquely expressed in specific subsets of EVs (30). Since DOX_EVs and SAL_EVs were composed of different subsets of EVs as indicated by the size, there was no appropriate protein to normalize the values.

Intriguingly, the elevation of EV-associated PYGB, PYGL, and PYGM after DOX treatment was proportionally higher than cTnI, ALT, and CKMM, respectively (Figures 6A-6F), suggesting that GPs are more sensitive than the conventional biomarkers to detect DOXinduced tissue injuries. Moreover, by measuring EV_PYGB by ELISA, we detected significant differences between SAL- and DOX-treated mice as early as $24 \mathrm{~h}$ post-treatment, whereas differences in cTnI were not detected until $72 \mathrm{~h}$ post-treatment (Figures $6 \mathrm{G}$ and 
$6 \mathrm{H})$. These data suggest that EV_PYGB is better than the conventional serological markers at early detection of DOX-induced cardiac injury.

\section{Discussion}

Oxidative stress-mediated tissue injury is a major side effect of chemotherapy that can lead to multiple organ dysfunction. However, biomarkers that are available to detect specific tissue injuries have not been linked to oxidative stress and are released only after cell death occurs. In this study, we exploited two properties of serum EVs that make them ideal early biomarkers for chemotherapy-induced tissue injury: lipid peroxidation, and tissue-specific proteins inside EVs. Here, we demonstrated for the first time that EVs released from normal tissues affected by DOX have aberrant membrane morphology and higher protein-bound 4HNE levels. Proteomic analysis revealed that PYGB, PYGM, and PYGL are specific indicators for the tissue of origin of EVs released post-chemotherapy, which are brain/heart, skeletal muscle, and liver, respectively. Importantly, serum EVs are indicators of the level of tissue oxidative stress, as evidenced by the attenuation of $4 \mathrm{HNE}$ protein adduction, as well as the decreased release of EVs from heart tissue with enhanced antioxidant capacity. Thus, measurement of EV-associated protein-bound $4 \mathrm{HNE}$ and the tissue-specific cargo proteins may overcome the limitations encountered with the use of serum oxidative stress markers in terms of stability, extracellular oxidation, and specificity for the target tissue oxidative status.

Lipid peroxidation products are one of the major effects of treatment with DOX. With TEM, we observed that the DOX_EV membrane was irregular. Changes associated with the DOX_EV membrane morphology might be a consequence of lipid peroxidation, which can influence the surface area, thickness, and permeability of the lipid membrane (31-33). The larger size of DOX_EVs compared to SAL_EVs may result from a property of the lipid membrane, or the shift from exosome release to microvesicle release under oxidative stress. The evidence for lipid peroxidation on the EV surface was strengthened by the observation of elevated protein-bound 4HNE after DOX treatment. The level of protein-bound 4HNE in EVs increased within $24 \mathrm{~h}$ after DOX treatment, which is consistent with our previous reports, in which $4 \mathrm{HNE}$ adduction accumulated in cardiac tissues as early as $3 \mathrm{~h}$, peaking at $6 \mathrm{~h}$ and subsequently declining at $24 \mathrm{~h}(10,34)$. The disappearance of protein-bound 4HNE from the tissue and its appearance in EVs at $24 \mathrm{~h}$ prompts speculation that EV release may provide a mechanism to remove oxidatively modified protein, which is highly toxic to cells.

The proteomic profiling revealed TfR1 and MHC-I as uniquely expressed proteins in SAL_EVs but not in DOX_EVs. TfR1 is released in the form of exosomes during erythrocyte maturation (35-37). The disappearance of TfR1 from DOX_EVs is consistent with the myelosuppressive effect of DOX, which peaks by day 3 post-treatment and is associated with a $90 \%$ reduction of total bone marrow cells (38). MHC-I, on the other hand, is required for selection of naïve $\mathrm{CD} 8^{+} \mathrm{T}$ lymphocytes, which occurs in the thymus and other immune-related tissues, and for presentation of intracellular peptide-antigens to cytotoxic $\left(\mathrm{CD}^{+}\right)$T lymphocytes (39). Moreover, peripheral MHC-I is also involved in the repopulation of $\mathrm{CD}^{+} \mathrm{T}$ cells outside the thymus (40). In the present study, loss of MHC-I from DOX_EVs suggests an interference with the maintenance of T cell survival in peripheral blood, potentiating the immunosuppressive effect of DOX on any adaptive 
immune response. In contrast to SAL_EVs, proteins uniquely expressed in DOX_EVs are related to the oxidative and metabolic stress response. Hp functions as an antioxidant by binding to extra-corpuscular hemoglobin during hemolysis. This action impedes heme-iron exposure to an oxygenated environment, averting the Fenton reaction, which leads to ROS production (41).

Metabolic alteration also occurs in many tissues after DOX treatment. Gene expression (42) and metabolomics (43) analyses of DOX-treated cardiac tissue show that myocardial metabolism switches from fatty acid oxidation to anaerobic glycolysis. Glycogenolysis provides alternative source of glucose derived from glycogen breakdown during stress conditions. Glycogenolysis is regulated by one of 3 isoforms of GP in a tissue-specific manner (44). The current study demonstrates that all three GP isoforms are expressed in DOX_EVs. Interestingly, PYGB, PYGM, and PYGL were depleted from heart, skeletal muscle, and liver, respectively, after DOX treatment, suggesting that the EV-encapsulated PYGB, PYGM, and PYGL were released from those particular tissues. However, we did not observe a decrease of PYGB in the brain tissues of DOX-treated mice. Because DOX does not cross the blood-brain barrier, our data indicate that EV-associated GPs are released from the tissues that are directly affected by the drug. Therefore, the data suggest that EVs containing a specific GP may be an indicator of the injury of direct target tissues from DOX, specifically glycogenolysis dysfunction, which might be an early sign of tissue injury during chemotherapy.

The strong association of EV release with oxidative stress was shown in the coimmunoprecipitation of 4HNE-adducted EVs with GP, suggesting that those EVs were released from tissues experiencing high oxidative stress. Moreover, mice with higher antioxidant capacity, such as MnSOD-overexpressing mice or MnP-pretreated mice, released lesser amounts of EVs following DOX treatment. Furthermore, a clinically approved cardioprotective drug that has antioxidant effects, DRZ, also reduced the amount of EV release from heart tissue. However, DRZ had a weaker effect on EV release than MnP had, which might be explained by the high preference for the mitochondria of MnP.

Compared to conventional serum biomarkers, EV-associated GP can detect chemotherapyinduced tissue injury earlier, which would allow the initiation of preventive intervention to preserve normal tissue function before cell death occurs. However, because our study is based on normal mice without cancer, our result is only valid for predicting tissue injury in patients that no longer have tumors, such as long-term cancer survivors. In patients that still have tumors, EV-associated GP may also be released from the tumor itself. Further studies in tumor-bearing mice should be performed to confirm this speculation.

Overall, our study is the first to demonstrate that DOX induces the release of EVs with higher levels of protein-bound 4HNE, and that the presence of EVs containing PGYB is robust and their appearance occurs prior to that of cardiac troponin. Importantly, pretreatment with mitochondrial selective antioxidants can be an effective means for intervention. Thus, EVs can be used to predict antioxidant capacity against chemotherapy of individual patients and to determine the dose of chemotherapy that will avoid normal tissue injury. 


\section{Supplementary Material}

Refer to Web version on PubMed Central for supplementary material.

\section{Acknowledgments}

The authors thank Professors Edward Kasarskis, William St. Clair, and Subbarao Bondada for valuable discussions; Wei Zhang for blood collection technique; Ana Bastos-Carvalho for assisting with EV TEM sample preparation; Steven Rheiner for assisting with dynamic light scattering analysis; and the MCC Research Communication Office for the graphic/editing support.

Financial Support: This study was supported by the National Institutes of Health (RO1 CA139843 to DK St. Clair), the University of Kentucky Markey Cancer Center's Redox Metabolism Shared Resource Facility (P30 CA177558), and the Royal Thai Government Scholarship (Ministry of Science and Technology) to C. Yarana. LC/MS-MS equipment was acquired using a National Center for Research Resources High-End Instrumentation grant (1S10RR029127 to H. Zhu).

\section{Abbreviations list}

4HNE

ALT

CKMM

cTnI

DOX

DRZ

EVs

GP

Hp

MHC-I

MnP

MnSOD

PYGB

PYGL

PYGM

RNS

ROS

SAL

TEM

\section{4-hydroxynonenal}

alanine transferase

creatine kinase isoenzyme MM

cardiac troponin I

doxorubicin

dexrazoxane

extracellular vesicles

glycogen phosphorylase

haptoglobin

class I histocompatibility antigen

$\mathrm{Mn}(\mathrm{III})$ meso-tetrakis ( $N$-(n-butoxyethyl)pyridium-2-yl)porphyrin, MnTnBuOE-2-PyP ${ }^{5+}$

manganese superoxide dismutase

brain/heart glycogen phosphorylase

liver glycogen phosphorylase

muscle glycogen phosphorylase

reactive nitrogen species

reactive oxygen species

saline

transmission electron microscopy 


\section{References}

1. ACS. [cited September, 2016] Cancer Treatment and Survivorship Facts and Figures 2014-2015. 2014. Available from: http://www.cancer.org

2. Partridge AH, Winer EP. Long-term complications of adjuvant chemotherapy for early stage breast cancer. Breast disease. 2004; 21:55-64. [PubMed: 15687723]

3. Hassett MJ, O'Malley AJ, Pakes JR, Newhouse JP, Earle CC. Frequency and cost of chemotherapyrelated serious adverse effects in a population sample of women with breast cancer. Journal of the National Cancer Institute. 2006; 98(16):1108-17. DOI: 10.1093/jnci/djj305 [PubMed: 16912263]

4. Shelburne N, Adhikari B, Brell J, Davis M, Desvigne-Nickens P, Freedman A, et al. Cancer treatment-related cardiotoxicity: current state of knowledge and future research priorities. Journal of the National Cancer Institute. 2014; 106(9)doi: 10.1093/jnci/dju232

5. Volkova M, Russell R 3rd. Anthracycline cardiotoxicity: prevalence, pathogenesis and treatment. Current cardiology reviews. 2011; 7(4):214-20. [PubMed: 22758622]

6. Shakir DK, Rasul KI. Chemotherapy induced cardiomyopathy: pathogenesis, monitoring and management. Journal of clinical medicine research. 2009; 1(1):8-12. DOI: 10.4021/ jocmr2009.02.1225 [PubMed: 22505958]

7. Tian S, Hirshfield KM, Jabbour SK, Toppmeyer D, Haffty BG, Khan AJ, et al. Serum biomarkers for the detection of cardiac toxicity after chemotherapy and radiation therapy in breast cancer patients. Frontiers in oncology. 2014; 4:277.doi: 10.3389/fonc.2014.00277 [PubMed: 25346912]

8. Dodos F, Halbsguth T, Erdmann E, Hoppe UC. Usefulness of myocardial performance index and biochemical markers for early detection of anthracycline-induced cardiotoxicity in adults. Clinical research in cardiology : official journal of the German Cardiac Society. 2008; 97(5):318-26. DOI: 10.1007/s00392-007-0633-6 [PubMed: 18193371]

9. Yen HC, Oberley TD, Vichitbandha S, Ho YS, St Clair DK. The protective role of manganese superoxide dismutase against adriamycin-induced acute cardiac toxicity in transgenic mice. The Journal of clinical investigation. 1996; 98(5):1253-60. DOI: 10.1172/JCI118909 [PubMed: 8787689]

10. Chaiswing L, Cole MP, Ittarat W, Szweda LI, St Clair DK, Oberley TD. Manganese superoxide dismutase and inducible nitric oxide synthase modify early oxidative events in acute adriamycininduced mitochondrial toxicity. Molecular cancer therapeutics. 2005; 4(7):1056-64. DOI: 10.1158/1535-7163.MCT-04-0322 [PubMed: 16020663]

11. Zhao Y, Miriyala S, Miao L, Mitov M, Schnell D, Dhar SK, et al. Redox proteomic identification of HNE-bound mitochondrial proteins in cardiac tissues reveals a systemic effect on energy metabolism after doxorubicin treatment. Free radical biology \& medicine. 2014; 72:55-65. DOI: 10.1016/j.freeradbiomed.2014.03.001 [PubMed: 24632380]

12. Miriyala S, Thippakorn C, Chaiswing L, Xu Y, Noel T, Tovmasyan A, et al. Novel role of 4hydroxy-2-nonenal in AIFm2-mediated mitochondrial stress signaling. Free radical biology \& medicine. 2016; 91:68-80. DOI: 10.1016/j.freeradbiomed.2015.12.002 [PubMed: 26689472]

13. Li DL, Wang ZV, Ding G, Tan W, Luo X, Criollo A, et al. Doxorubicin Blocks Cardiomyocyte Autophagic Flux by Inhibiting Lysosome Acidification. Circulation. 2016; 133(17):1668-87. DOI: 10.1161/CIRCULATIONAHA.115.017443 [PubMed: 26984939]

14. Navarro-Yepes J, Burns M, Anandhan A, Khalimonchuk O, del Razo LM, Quintanilla-Vega B, et al. Oxidative stress, redox signaling, and autophagy: cell death versus survival. Antioxidants \& redox signaling. 2014; 21(1):66-85. DOI: 10.1089/ars.2014.5837 [PubMed: 24483238]

15. Sishi BJ, Loos B, van Rooyen J, Engelbrecht AM. Doxorubicin induces protein ubiquitination and inhibits proteasome activity during cardiotoxicity. Toxicology. 2013; 309:23-9. DOI: 10.1016/ j.tox.2013.04.016 [PubMed: 23639627]

16. Lawson C, Vicencio JM, Yellon DM, Davidson SM. Microvesicles and exosomes: new players in metabolic and cardiovascular disease. The Journal of endocrinology. 2016; 228(2):R57-71. DOI: 10.1530/JOE-15-0201 [PubMed: 26743452] 
17. Nawaz M, Camussi G, Valadi H, Nazarenko I, Ekstrom K, Wang X, et al. The emerging role of extracellular vesicles as biomarkers for urogenital cancers. Nature reviews Urology. 2014; 11(12): 688-701. DOI: 10.1038/nrurol.2014.301 [PubMed: 25403245]

18. Yeh YY, Ozer HG, Lehman AM, Maddocks K, Yu L, Johnson AJ, et al. Characterization of CLL exosomes reveals a distinct microRNA signature and enhanced secretion by activation of BCR signaling. Blood. 2015; 125(21):3297-305. DOI: 10.1182/blood-2014-12-618470 [PubMed: 25833959]

19. T LR, Sanchez-Abarca LI, Muntion S, Preciado S, Puig N, Lopez-Ruano G, et al. MSC surface markers (CD44, CD73, and CD90) can identify human MSC-derived extracellular vesicles by conventional flow cytometry. Cell communication and signaling : CCS. 2016; 14:2.doi: 10.1186/ s12964-015-0124-8 [PubMed: 26754424]

20. Sharma A, Khatun Z, Shiras A. Tumor exosomes: cellular postmen of cancer diagnosis and personalized therapy. Nanomedicine. 2016; 11(4):421-37. DOI: 10.2217/nnm.15.210 [PubMed: 26784674]

21. Wiseman LR, Spencer CM. Dexrazoxane. A review of its use as a cardioprotective agent in patients receiving anthracycline-based chemotherapy. Drugs. 1998; 56(3):385-403. [PubMed: 9777314]

22. Povero D, Eguchi A, Li H, Johnson CD, Papouchado BG, Wree A, et al. Circulating extracellular vesicles with specific proteome and liver microRNAs are potential biomarkers for liver injury in experimental fatty liver disease. PloS one. 2014; 9(12):e113651.doi: 10.1371/journal.pone. 0113651 [PubMed: 25470250]

23. Thery C, Amigorena S, Raposo G, Clayton A. Isolation and characterization of exosomes from cell culture supernatants and biological fluids. Curr Protoc Cell Biol. 2006; :22. Chapter 3: Unit 3. doi: 10.1002/0471143030.cb0322s30 [PubMed: 18228490]

24. Butterfield DA, Reed T, Perluigi M, De Marco C, Coccia R, Cini C, et al. Elevated protein-bound levels of the lipid peroxidation product, 4-hydroxy-2-nonenal, in brain from persons with mild cognitive impairment. Neuroscience letters. 2006; 397(3):170-3. DOI: 10.1016/j.neulet. 2005.12.017 [PubMed: 16413966]

25. Yang L, Gal J, Chen J, Zhu H. Self-assembled FUS binds active chromatin and regulates gene transcription. Proceedings of the National Academy of Sciences of the United States of America. 2014; 111(50):17809-14. DOI: 10.1073/pnas.1414004111 [PubMed: 25453086]

26. Kato K, Shimizu A, Kurobe N, Takashi M, Koshikawa T. Human brain-type glycogen phosphorylase: quantitative localization in human tissues determined with an immunoassay system. Journal of neurochemistry. 1989; 52(5):1425-32. [PubMed: 2651563]

27. Miriyala S, Spasojevic I, Tovmasyan A, Salvemini D, Vujaskovic Z, St Clair D, et al. Manganese superoxide dismutase, MnSOD and its mimics. Biochimica et biophysica acta. 2012; 1822(5):794814. DOI: 10.1016/j.bbadis.2011.12.002 [PubMed: 22198225]

28. Ichikawa Y, Ghanefar M, Bayeva M, Wu R, Khechaduri A, Naga Prasad SV, et al. Cardiotoxicity of doxorubicin is mediated through mitochondrial iron accumulation. The Journal of clinical investigation. 2014; 124(2):617-30. DOI: 10.1172/JCI72931 [PubMed: 24382354]

29. Hasinoff BB, Schnabl KL, Marusak RA, Patel D, Huebner E. Dexrazoxane (ICRF-187) protects cardiac myocytes against doxorubicin by preventing damage to mitochondria. Cardiovascular toxicology. 2003; 3(2):89-99. [PubMed: 14501028]

30. Kowal J, Arras G, Colombo M, Jouve M, Morath JP, Primdal-Bengtson B, et al. Proteomic comparison defines novel markers to characterize heterogeneous populations of extracellular vesicle subtypes. Proceedings of the National Academy of Sciences of the United States of America. 2016; 113(8):E968-77. DOI: 10.1073/pnas.1521230113 [PubMed: 26858453]

31. Weber G, Charitat T, Baptista MS, Uchoa AF, Pavani C, Junqueira HC, et al. Lipid oxidation induces structural changes in biomimetic membranes. Soft matter. 2014; 10(24):4241-7. DOI: 10.1039/c3sm52740a [PubMed: 24871383]

32. Heuvingh J, Bonneau S. Asymmetric oxidation of giant vesicles triggers curvature-associated shape transition and permeabilization. Biophysical journal. 2009; 97(11):2904-12. DOI: 10.1016/ j.bpj.2009.08.056 [PubMed: 19948119] 
33. Sankhagowit S, Wu SH, Biswas R, Riche CT, Povinelli ML, Malmstadt N. The dynamics of giant unilamellar vesicle oxidation probed by morphological transitions. Biochimica et biophysica acta. 2014; 1838(10):2615-24. DOI: 10.1016/j.bbamem.2014.06.020 [PubMed: 24998358]

34. Chaiswing L, Cole MP, St Clair DK, Ittarat W, Szweda LI, Oberley TD. Oxidative damage precedes nitrative damage in adriamycin-induced cardiac mitochondrial injury. Toxicologic pathology. 2004; 32(5):536-47. [PubMed: 15605432]

35. Johnstone RM, Adam M, Hammond JR, Orr L, Turbide C. Vesicle formation during reticulocyte maturation. Association of plasma membrane activities with released vesicles (exosomes). The Journal of biological chemistry. 1987; 262(19):9412-20. [PubMed: 3597417]

36. Marsee DK, Pinkus GS, Yu H. CD71 (transferrin receptor): an effective marker for erythroid precursors in bone marrow biopsy specimens. American journal of clinical pathology. 2010; 134(3):429-35. DOI: 10.1309/AJCPCRK3MOAOJ6AT [PubMed: 20716799]

37. Johnstone RM, Bianchini A, Teng K. Reticulocyte maturation and exosome release: transferrin receptor containing exosomes shows multiple plasma membrane functions. Blood. 1989; 74(5): 1844-51. [PubMed: 2790208]

38. Bally MB, Nayar R, Masin D, Cullis PR, Mayer LD. Studies on the myelosuppressive activity of doxorubicin entrapped in liposomes. Cancer chemotherapy and pharmacology. 1990; 27(1):13-9. [PubMed: 2245488]

39. Markiewicz MA, Brown I, Gajewski TF. Death of peripheral CD8+ T cells in the absence of MHC class I is Fas-dependent and not blocked by Bcl-xL. European journal of immunology. 2003; 33(10):2917-26. DOI: 10.1002/eji.200324273 [PubMed: 14515276]

40. Nesic D, Vukmanovic S. MHC class I is required for peripheral accumulation of CD8+ thymic emigrants. Journal of immunology. 1998; 160(8):3705-12.

41. Schaer DJ, Buehler PW, Alayash AI, Belcher JD, Vercellotti GM. Hemolysis and free hemoglobin revisited: exploring hemoglobin and hemin scavengers as a novel class of therapeutic proteins. Blood. 2013; 121(8):1276-84. DOI: 10.1182/blood-2012-11-451229 [PubMed: 23264591]

42. Berthiaume JM, Wallace KB. Persistent alterations to the gene expression profile of the heart subsequent to chronic Doxorubicin treatment. Cardiovascular toxicology. 2007; 7(3):178-91. DOI: 10.1007/s12012-007-0026-0 [PubMed: 17901561]

43. Carvalho RA, Sousa RP, Cadete VJ, Lopaschuk GD, Palmeira CM, Bjork JA, et al. Metabolic remodeling associated with subchronic doxorubicin cardiomyopathy. Toxicology. 2010; 270(2-3): 92-8. DOI: 10.1016/j.tox.2010.01.019 [PubMed: 20132857]

44. Adeva-Andany MM, Gonzalez-Lucan M, Donapetry-Garcia C, Fernandez-Fernandez C, Ameneiros-Rodriguez E. Glycogen metabolism in humans. BBA clinical. 2016; 5:85-100. DOI: 10.1016/j.bbacli.2016.02.001 [PubMed: 27051594] 


\section{Translational relevance}

Significant advances in the efficacy of cancer therapy have been accompanied by an escalation in side effects that result from therapy-induced injury to normal tissues. The number of cancer survivors is now 14.5 million in the United States alone, and is expected to rise by $31 \%$ to 19 million by 2024 (www.cancer.org). Cardiac injury is a major cause of death in cancer survivors, but the current indicators of cardiac injury are detectable only after significant damage has occurred. Thus, sensitive biomarkers are needed to permit early intervention to prevent long-term cardiac injury after chemotherapy. In response to stress conditions, tissues release extracellular vesicles into circulation. The presence of tissue-specific glycogen phosphorylase in circulating extracellular vesicles and the reduction of glycogen phosphorylase, brain (PYGB) in cardiac tissue following chemotherapy makes it a clinically attractive diagnostic biomarker for therapeutic interventions. 


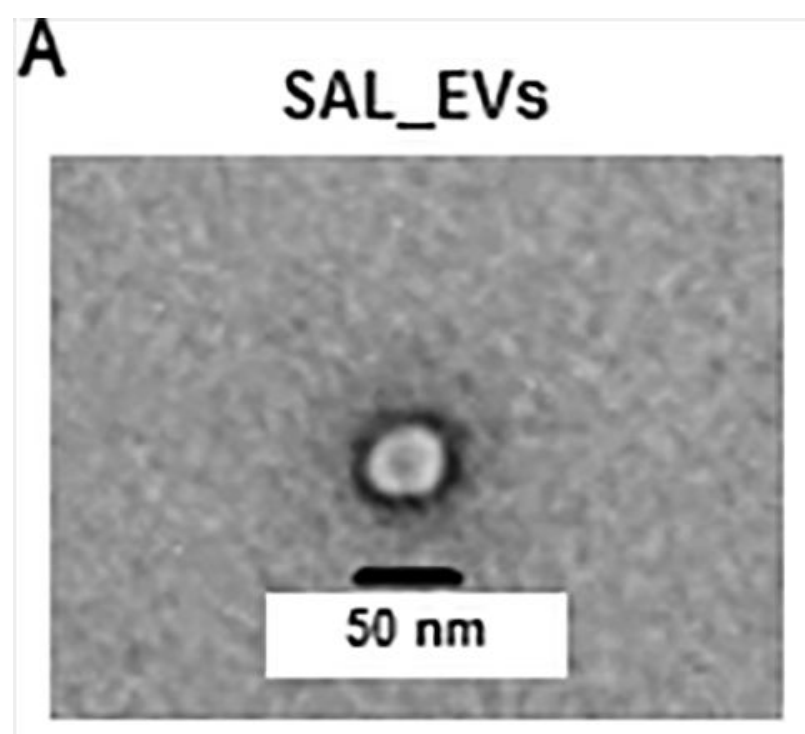

\section{DOX_EVs}

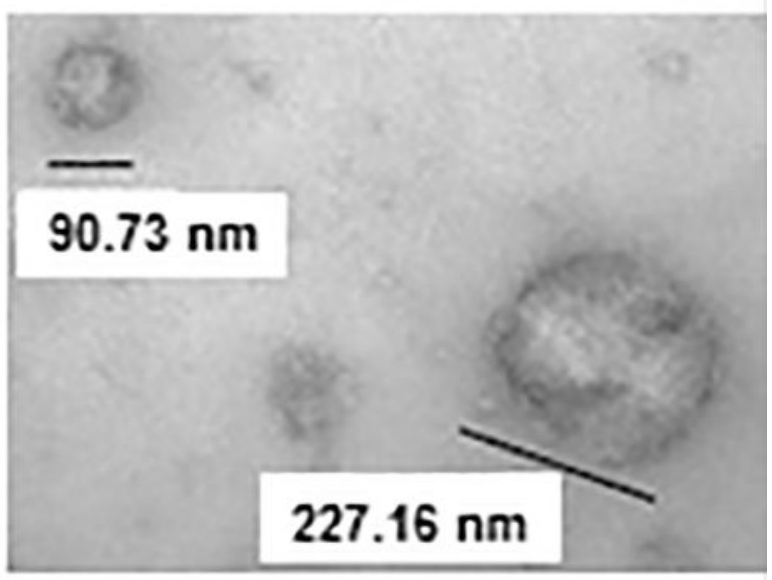

B

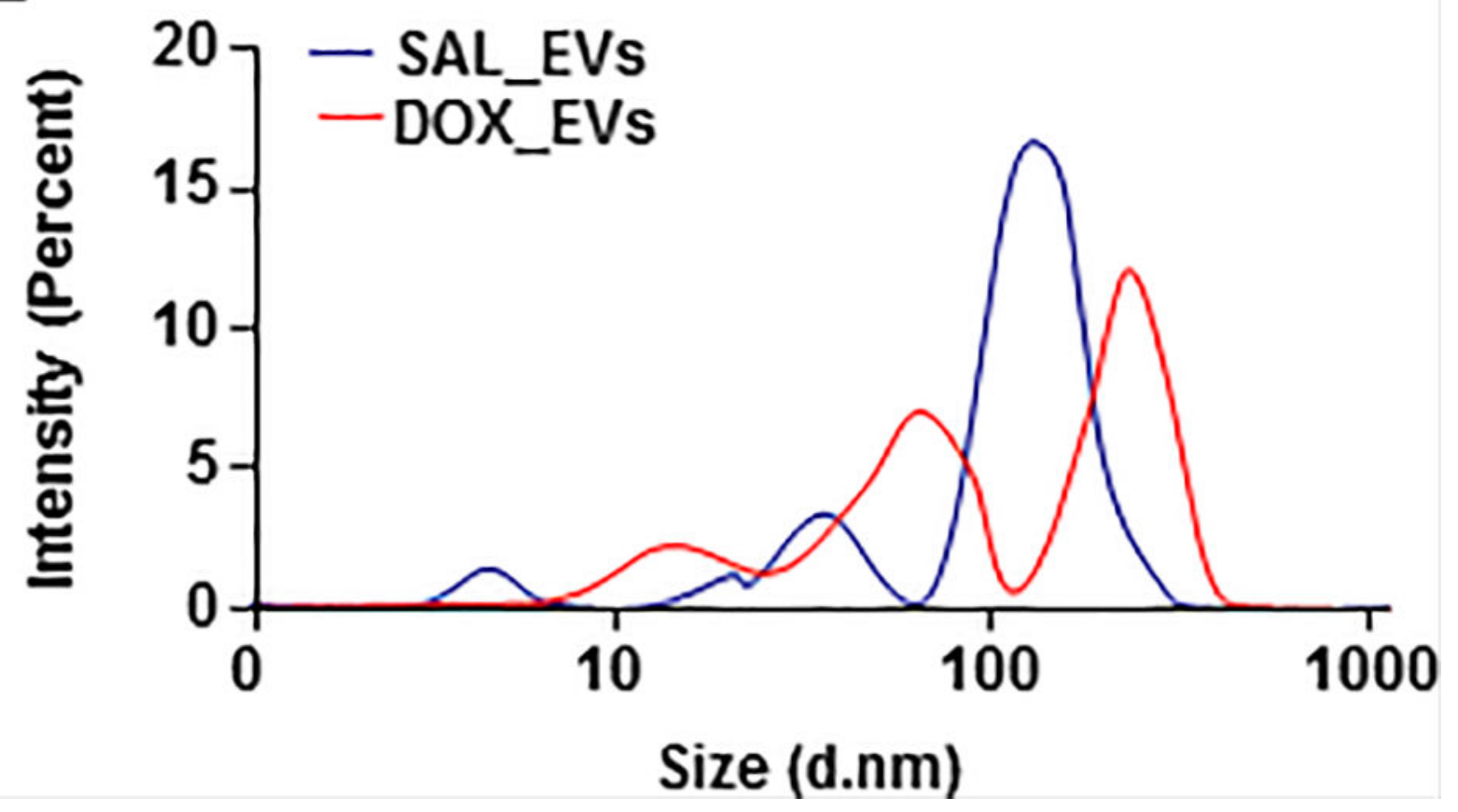

Figure 1. Morphology and size of DOX_EVs were different from SAL_EVs

(A) Representative electron micrograph of mouse serum EVs (high magnification, $\times 49,000$ ).

The numbers represent the diameter of the vesicles. (B) Graphic representation of the distribution in EV size. Presented data are the percent intensity of scattered light of EVs from mouse serum. Blue line represents SAL_EVs' size distribution. Red line represents DOX_EVs' size distribution 
A

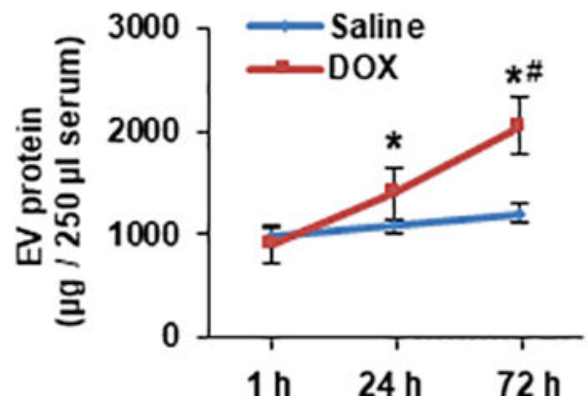

B

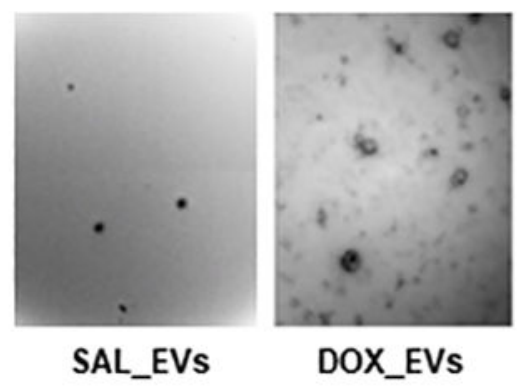

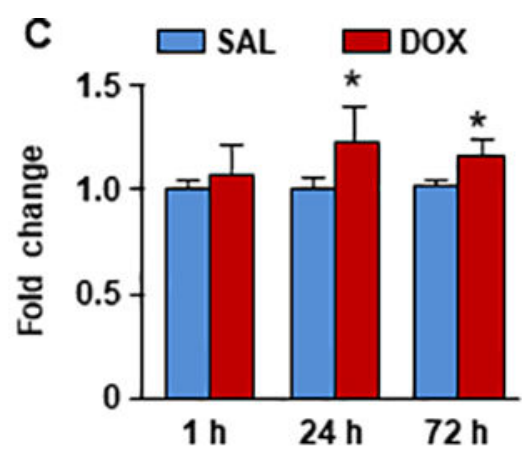

Figure 2. DOX-treated mouse serum contained more EVs and higher level of protein-bound 4HNE than SAL-treated mouse serum

(A) EV protein levels in $250 \mu \mathrm{l}$ serum from saline-treated (blue line) and DOX-treated (red line) mice (mean $\pm \mathrm{SD}, \mathrm{n}=5-6,{ }^{*} \mathrm{p}<0.01$ vs $1 \mathrm{~h}$, \# $\mathrm{p}<0.01$ vs Saline. (B) Representative electron micrograph of mouse serum EVs (low magnification, $\times 23,000$ ) at $72 \mathrm{~h}$ post treatment. (C) Fold change of protein-bound 4HNE in EVs from mice treated with saline (SAL) or DOX for $1 \mathrm{~h}, 24 \mathrm{~h}$ and $72 \mathrm{~h}$ (mean $\pm \mathrm{SD}, * \mathrm{p}<0.05$ vs Saline at the same time point. 
A

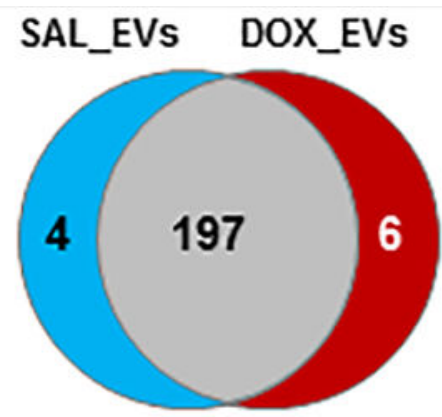

B

Proteins that are only expressed in SAL_EV

\begin{tabular}{lllr}
\hline Protein & Protein Name & \multicolumn{2}{c}{ Score Coverage } \\
\hline Q62351 & $\begin{array}{l}\text { Transferrin receptor protein } \\
1\end{array}$ & 884.79 & 36.04 \\
\hline P14430 & $\begin{array}{l}\mathrm{H}-2 \text { class I histocompatibility } \\
\text { antigen, Q8 alpha chain }\end{array}$ & 57.63 & 4.29 \\
\hline P06339 & $\begin{array}{l}\mathrm{H}-2 \text { class I histocompatibility } \\
\text { antigen, D-37 alpha chain }\end{array}$ & 57.63 & 3.92 \\
\hline P01897 & $\begin{array}{l}\mathrm{H}-2 \text { class I histocompatibility } \\
\text { antigen, L-D alpha chain }\end{array}$ & 57.04 & 3.59 \\
\hline
\end{tabular}

\begin{tabular}{lllr} 
C & \multicolumn{3}{c}{ Proteins that are only expressed in DOX_EV } \\
\hline Protein & Protein Name & \multicolumn{2}{c}{ Score Coverage } \\
\hline Q61646 & Haptoglobin & 231.11 & 31.70 \\
\hline Q9WUB33 & $\begin{array}{l}\text { Glycogen phosphorylase, } \\
\text { muscle form }\end{array}$ & 166.80 & 25.06 \\
\hline Q8C194 & $\begin{array}{l}\text { Glycogen phosphorylase, } \\
\text { brain form }\end{array}$ & 172.00 & 12.22 \\
\hline O88990 & Alpha-actinin-3 & 108.98 & 3.67 \\
\hline Q9ET01 & $\begin{array}{l}\text { Glycogen phosphorylase, } \\
\text { liver form }\end{array}$ & 80.71 & 4.59 \\
\hline P52480 & Pyruvate kinase PKM & 59.36 & 6.97 \\
\hline
\end{tabular}

Figure 3. Proteomic profiling of circulating EVs

(A) Venn diagram showing the number of proteins found in EVs from SAL (blue) and DOXtreated (red) mice. (B) List of proteins found exclusively in EVs from SAL-treated mice. (C) List of proteins found exclusively in EVs from DOX-treated mice. Score = ion score of the peptide; Coverage $=\%$ of protein sequence covered by identified peptide. 

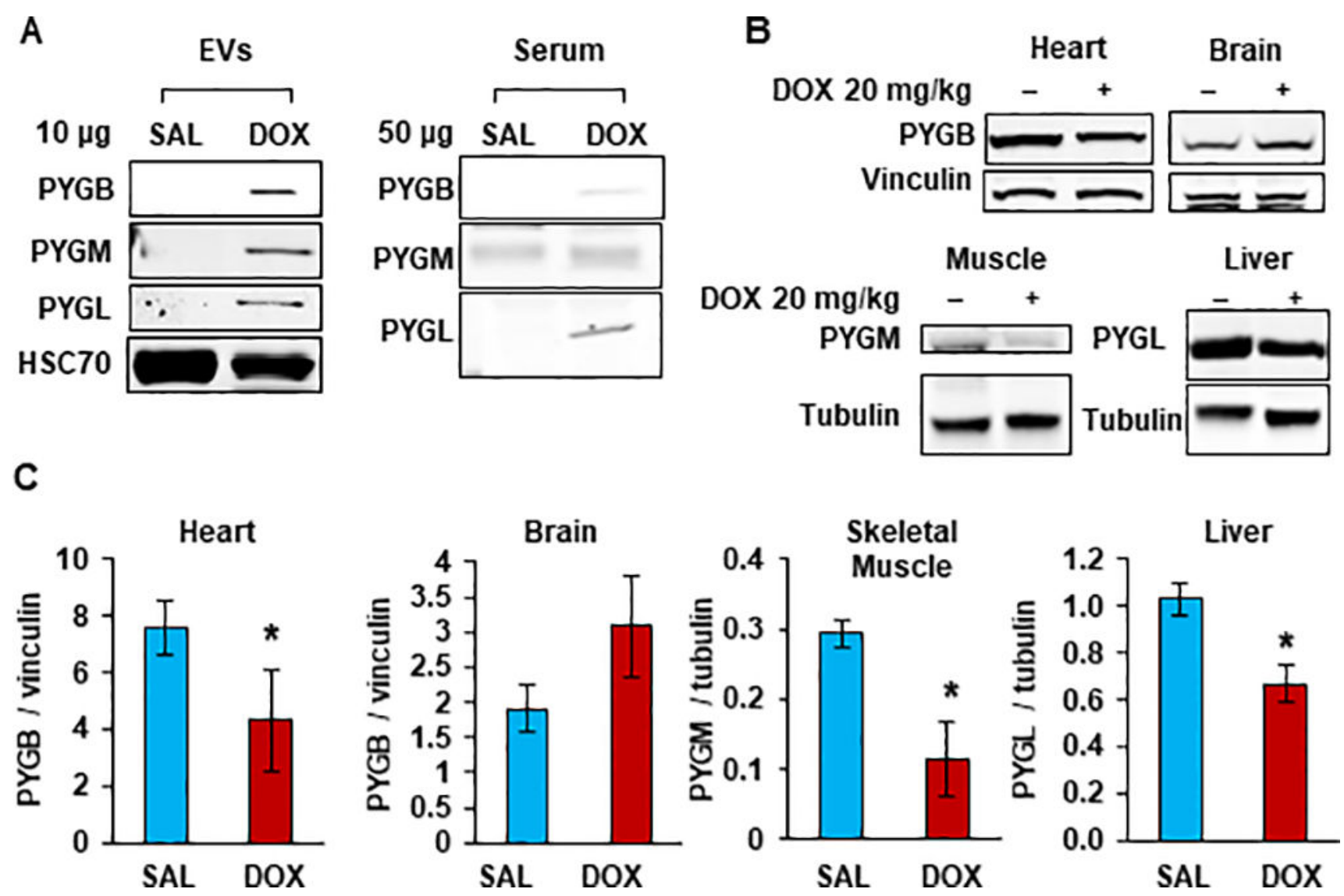

Figure 4. EV-containing glycogen phosphorylase isoforms are associated with DOX-induced tissue injuries

(A) Western blot of PYGB, PYGM, PYGL obtained from EVs isolated by sucrose gradient centrifugation and from whole serum protein, HSC70 was used as an EV marker and loading control for EVs. (B) Western blot of PYGB, PYGM and PYGL levels obtained from heart, brain, skeletal muscle and liver lysates isolated from Saline- and DOX-treated mice.

Vinculin was used as a loading control for heart and brain tissues; beta tubulin was used as a loading control for skeletal muscle and liver. (C) Graphic representation of western blot band intensities of PYGB, PYGM and PYGL in the relevant highly enriched tissues and normalized by the appropriate loading control (mean $\pm \mathrm{SD}, \mathrm{n}=6, * \mathrm{p}<0.05$ ). 
A

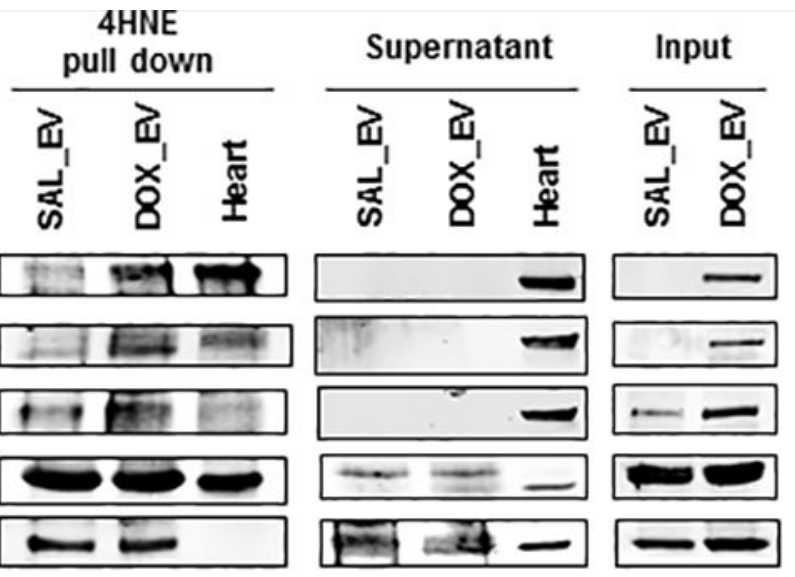

B

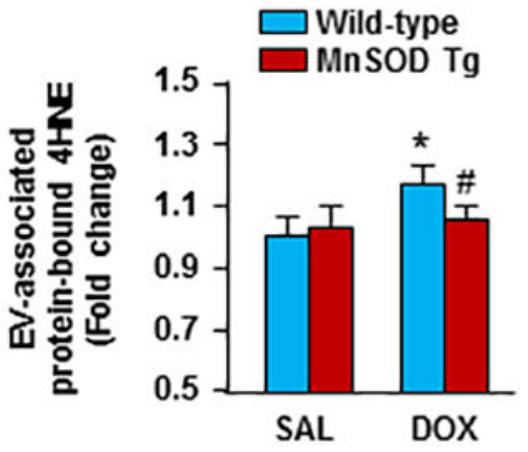

C

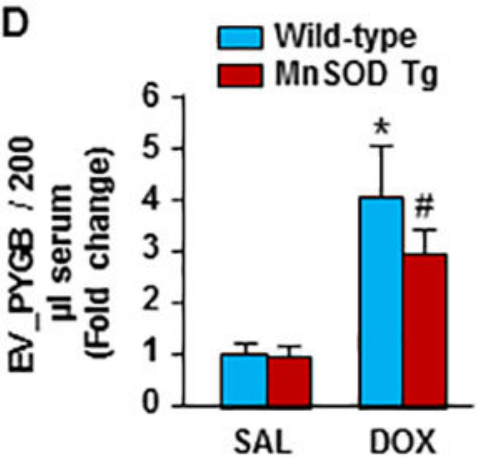

E

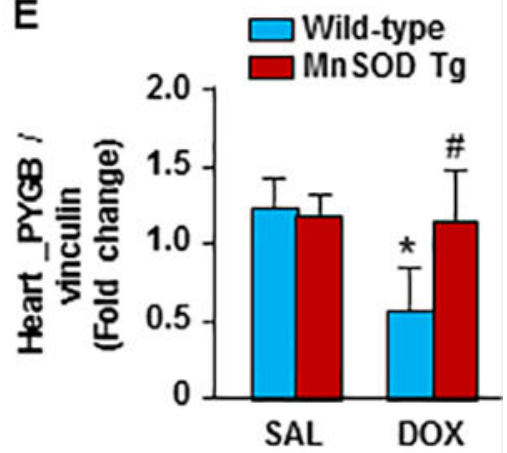

$\mathbf{F}$

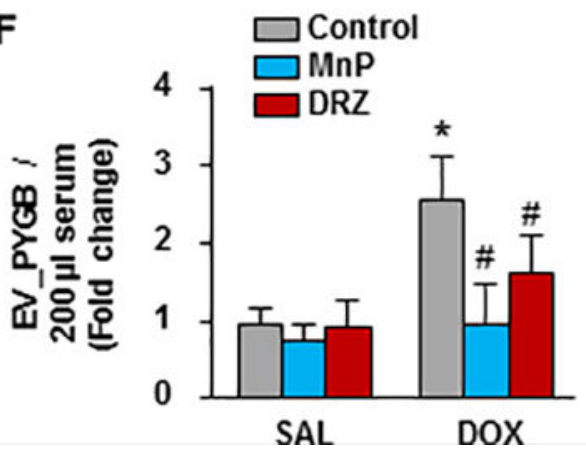

G

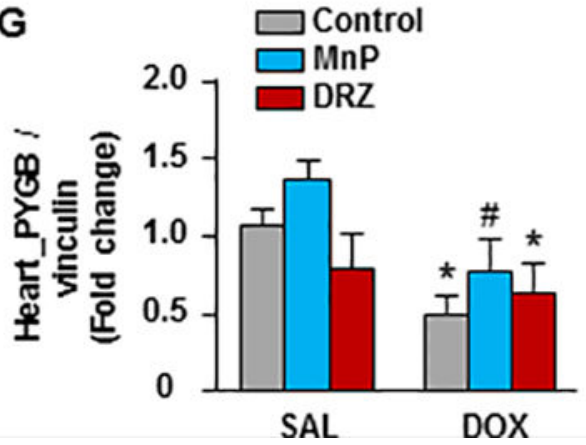

Figure 5. EVs with 4HNE adduction are released from direct target tissues of DOX, the release of which can be prevented by antioxidant enhancement

(A) Western blot to detect PYGB, PYGM, PYGL, as well as EV markers flotillin-1 and HSC70, in 4HNE-immunoprecipitated SAL_EVs and DOX_EVs and supernatant. Heart tissue lysate was used as a positive control. (B) The level of EV-associated protein-bound 4HNE from wild-type and MnSOD Tg mice after SAL or DOX treatment for $72 \mathrm{~h}$. (C) The level of EV-associated protein-bound $4 \mathrm{HNE}$ from mice pretreated with vehicle, MnP (2 $\mathrm{mg} / \mathrm{kg}$ ) or DRZ (200 mg/kg) $30 \mathrm{~min}$ before SAL or DOX treatment. (D-E) Western blot band intensities of PYGB in EVs from $200 \mu \mathrm{L}$ of serum, as well as PYGB normalized to vinculin from heart tissues of wild-type and MnSOD Tg mice treated with DOX. (F-G) Western blot band intensities of PYGB in EVs from $200 \mu \mathrm{L}$ of serum from mice pretreated with vehicle, MnP (2 mg/kg) or DRZ (200 mg/kg) $30 \mathrm{~min}$ before SAL or DOX treatment 
(mean $\pm \mathrm{SD}, \mathrm{n}=6-8, * \mathrm{p}<0.05$ vs Saline, \# $\mathrm{p}<0.05$ vs wild-type DOX (D-E) or control $\operatorname{DOX}(\mathrm{C}, \mathrm{F}-\mathrm{G})$ ). 
A

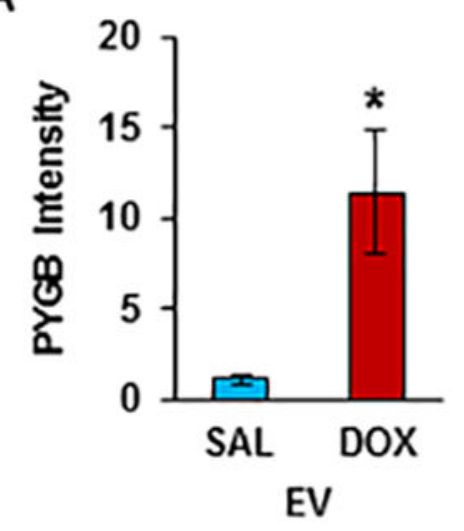

D

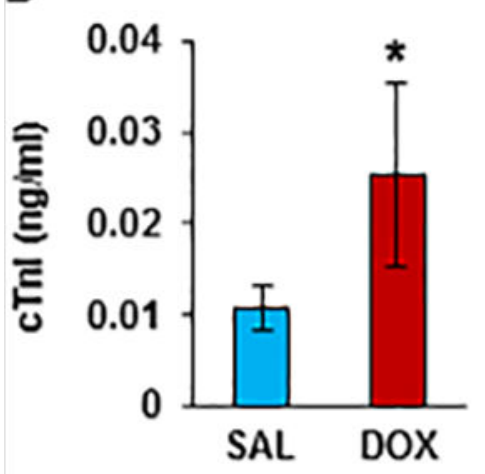

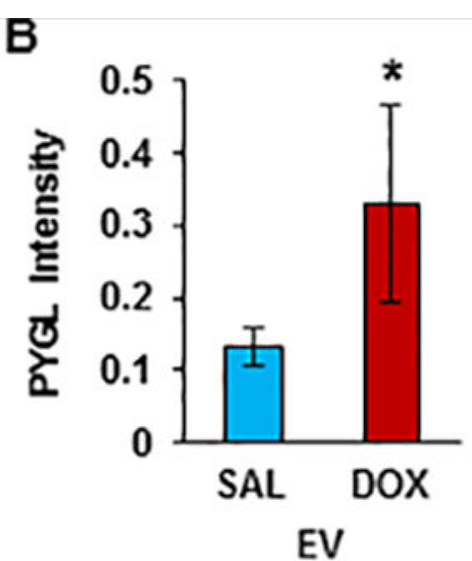

E

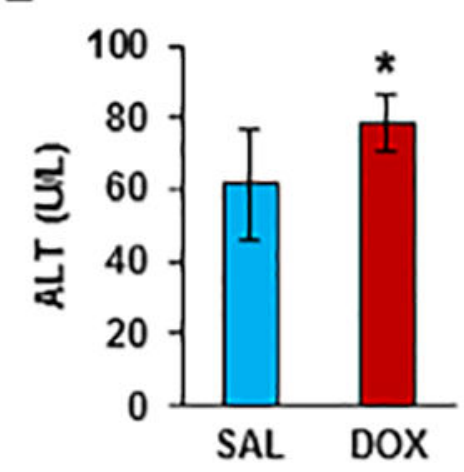

C

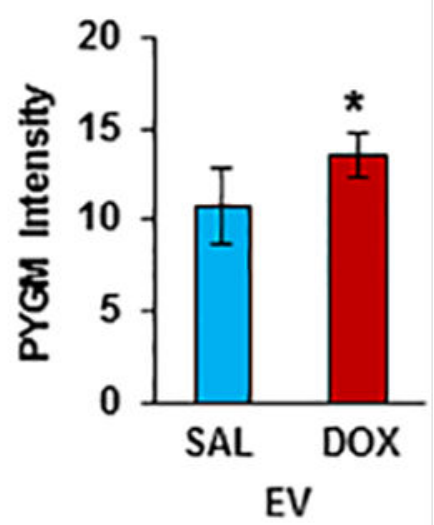

F

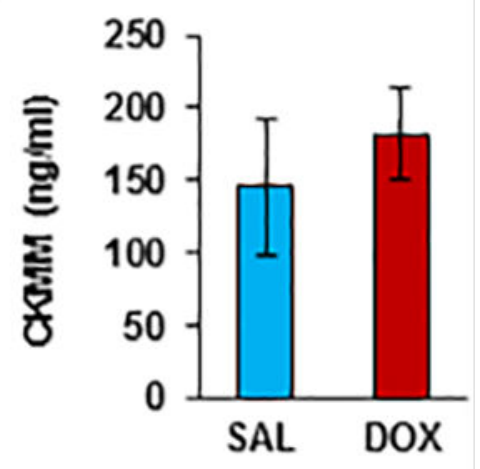

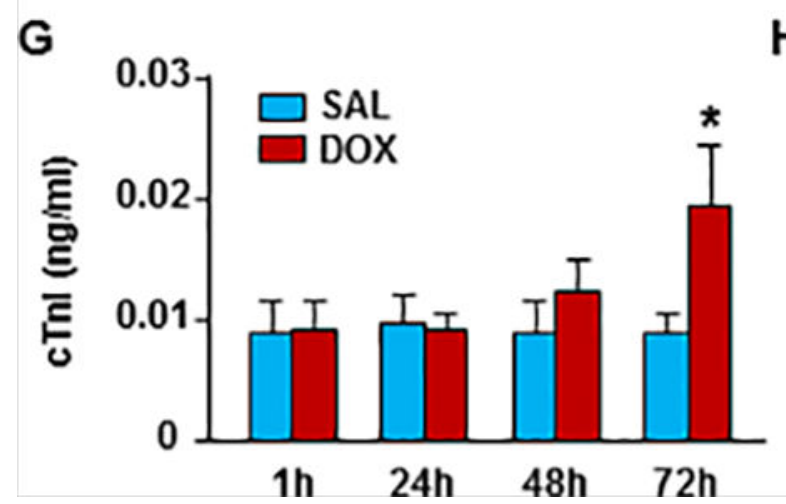

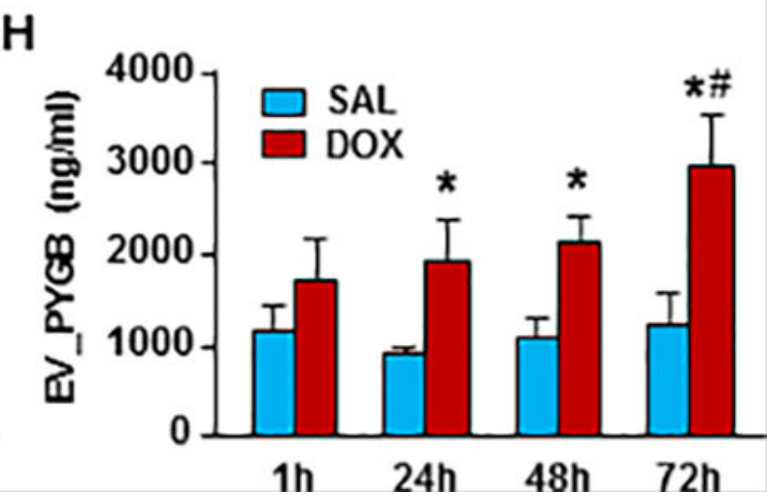

Figure 6. EV-associated glycogen phosphorylases are sensitive DOX-induced tissue injury markers

(A-C) Western blot band intensities for PYGB, PYGL, and PYGM levels (mean $\pm \mathrm{SD}, \mathrm{n}=$ 6 , * p $<0.05$ vs SAL). (D-F) Serum levels of cTnI, ALT, and CKMM measured by ELISA obtained from the SAL- and DOX-treated mice in the same set of samples presented in A-C. (G-H) Comparison of cTnI and EV_PYGB at different time points after SAL and DOX treatment (mean $\pm \mathrm{SD}, \mathrm{n}=6, * \mathrm{p}<0.05$ vs SAL at the same time point, \# $\mathrm{p}<0.05$ vs DOX at $1 \mathrm{~h}, 24 \mathrm{~h}$ and $48 \mathrm{~h})$. 